\title{
Influence of Drying Methods on Flour Quality and Cyanide Content of Cassava Root Tuber
}

\author{
Tamiru Kasaye Atlaw \\ Department of Food Engineering, College of Engineering, Debre Berhan University, Debre Berhan, Ethiopia \\ Email address: \\ tamirukasaye514@gmail.com

\section{To cite this article:} \\ Tamiru Kasaye Atlaw. Influence of Drying Methods on Flour Quality and Cyanide Content of Cassava Root Tuber. International Journal of \\ Nutrition and Food Sciences. Vol. 7, No. 4, 2018, pp. 142-147. doi: 10.11648/j.ijnfs.20180704.15
}

Received: July 17, 2018; Accepted: August 7, 2018; Published: August 22, 2018

\begin{abstract}
The aim of this particular work was to study effect of different drying methods on the quality attributes of cassava flour focusing on physico-chemical properties (moisture, water activity, $\mathrm{p}^{\mathrm{H}}$ and titratable acidity), functional properties (water and oil absorption capacity, bulk density, foaming capacity and stability) and also antinutritional factor specially cyanide content in dried cassava tuber. Losses were determined in flours after drying of slices. Prior to drying, samples were washed with clean water to remove adhering soil and other undesirable materials. The samples were sorted and hand-peeled using clean, sharp knives and then sliced into sizes of 2 to $2.5 \mathrm{~cm}$ in thickness. Drying methods like tray drying, oven drying and sun drying were investigated. The physico-chemical properties were $11.45,9.67,9.23$ of moisture content, $0.59,0.54,0.48$ of water activity, $6.55,6.74,6.92$ of $\mathrm{p}^{\mathrm{H}}, 2.35,2.36,2.33$ of titratable acidity for tray dried, oven dried and sun dried cassava flours respectively using different drying time. The low moisture observed for all prepared cassava flours is a good indicator of their potential to have longer shelf life. All prepared flours predict lower water activity $(<0.5)$. These shows using these drying methodologies and the respective drying time of the prepared flours were safe from microbial growth during storage time. The functional properties were $0.58,0.55,0.49 \mathrm{~g} / \mathrm{ml}, 0.64,0.78,0.65 \mathrm{ml} / \mathrm{g}, 2.11,2.03,1.85 \mathrm{ml} / \mathrm{g}, 2.45,2.73,2.55 \%$, and $2.34,2.13$, $1.97 \%$ of bulk density, water absorption capacity, oil absorption capacity, foam capacity and foam stability for tray dried, oven dried and sun dried cassava flours respectively. Sun dried cassava flour samples shows a lower cyanide content whereas tray dried cassava flour samples had a good functional property.
\end{abstract}

Keywords: Functional Properties, Phsico-chemical, Oven Drying, Sun Drying, Tray Drying

\section{Introduction}

Cassava (Manihot Esculenta Crantiz) is a dicotyledonous perennial woody shrub with an edible starchy root, belonging to the botanical family Euphorbiaceous. It belongs to roots and tuber crops that stores edible material in tuber [9], which belong to class of foods that basically provide energy in the human diet in the form of carbohydrates. Apart from its use as human food, cassava products also are popular in international trade under different forms such as dried chips, pellets, flour and starch, thus contributing to the economy of exporting countries [7, 11].

The advantage it has over other crops particularly, in many of the developing world is its outstanding ecological adaptation, low labour requirement, ease of cultivation and high yields. It is also widely cultivated because it can be successfully grown in poor soils, under conditions of marginal rainfall. It has the ability to grow with appreciable yield where many other crops would hardly survive. Cassava is the most widely distributed and cultivated in different parts of the low land tropics. It is the fourth most efficient crop plant, the most widely distributed and cultivated in different parts of the tropics among the tropical root crops (Amsalu, 2003). Africa is the largest center of production in cassava [8].

Although cassava is a staple it is poisonous in itsraw state as the plant contains cyanogenicglucosides. These glucosides are converted tohydrogen cyanide $(\mathrm{HCN})$ by an enzyme calledlinamarase, which is also present in cassava andacts on the glucosides when the plant cells are ruptured either when it is eaten or duringprocessing. For this reason, all cassava and cassava based products should pass through different effective processing methods to suppress adverse health effects that arises from cyanide toxicity as a result of cassava consumption and also to improve the nutritional profile and 
reduce the antinutritional factors that hinders normal absorption of nutrients. Hence the main objective of the present work was focused applying different drying methods to produce better quality and lower content of cyanide content cassava based flour.

\section{Materials and Methods}

\subsection{Raw Material}

The study samples, cassava (Qulle), were collected from shewarobit integrated research and development site of Debre Berhan University, north Shewa administrative zone, Shewarobit, Ethiopia. Shewarobit is located at about $225 \mathrm{~km}$ north east of Addis Ababa.

\subsection{Sample Preparation}

Sample preparation and drying were performed at Debre berehan University Chemical Engineering laboratory. Prior to drying, samples were washed withclean water to remove adhering soil and other undesirable materials. The samples were sorted and hand-peeled using Clean, sharp knivesandthen sliced into sizes of 2 to $2.5 \mathrm{~cm}$ in thickness.

Freshly sliced samples were spread equally in each methods of drying. Drying times were estimated by weighing the product at regular intervals to an estimated moisture contentof $10-12 \%$. The end of drying was estimated by slices brittleness and sampleweight. Drying was carried out using three techniques described below (Figure 1).

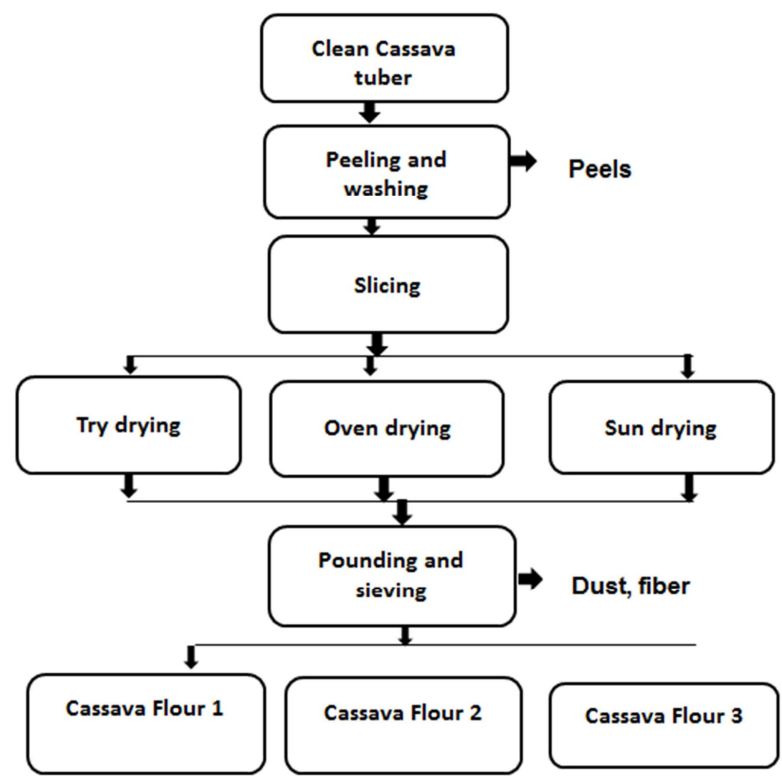

Figure 1. Preparation of different cassava flours.

\subsubsection{Tray Drier}

Using laboratory try drier (Figure 2) samples were put using tray. As much as possible on the tray we tried to use uniform thickness for drying in order to avoid the drying variation.

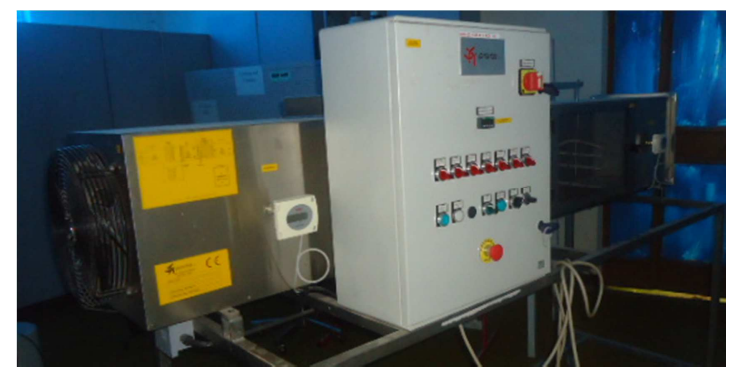

Figure 2. Tray Dryer.

\subsubsection{Oven Drying}

The prepared sliced cassava tuberwas put in an ovento be dried at $55^{\circ} \mathrm{C}$. The dried cassava slice milled in a universal millto obtain the flour followed bysieving using a sieve with 710-micron sieve (Endecotts LTD., London England)and then kept in poly ethylene plastic bag (Figure 3) until ready for further use.

\subsubsection{Sun Drying}

Solar-drying is achieved by direct sun radiation at the open field. In order to avoid contamination of outside environment we tied to cover the outer part using cloth.

\subsection{Determination of Physico- Chemical Properties}

\subsubsection{Moisture Determination}

Moisture contents of the dried sliced cassava tubers were determined according to [3], using the official method 925.05. The dishes used for the moisture determination were dried at $130^{\circ} \mathrm{C}$ for $1 \mathrm{hr}$ in drying oven and placed in desiccators for about $30 \mathrm{~min}$. The mass of each dishes was measured $\left(\mathrm{M}_{1}\right)$ and about $5 \mathrm{~g}$ of the sample was weighed in to each of the dishes $\left(\mathrm{M}_{2}\right)$. The sample was then mixed thoroughly and dried at $100^{\circ} \mathrm{C}$ for $6 \mathrm{hr}$. After drying is completed, the mass was measured $\left(\mathrm{M}_{3}\right)$. The moisture content was calculated from the equation:

$$
\text { Moisture }\left(\% \frac{w}{w}\right)=\frac{M 2-M 3}{M 2-M 1} X 100
$$

$\mathrm{M}_{1}$ : mass of the dish, $\mathrm{M}_{2}$ : mass of the dish and the sample before drying, and $\mathrm{M}_{3}$ : mass of the dish and the sample after drying.

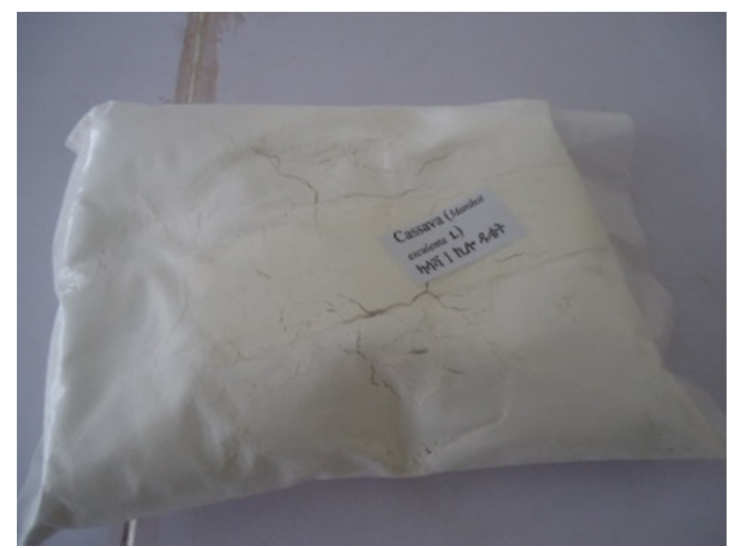




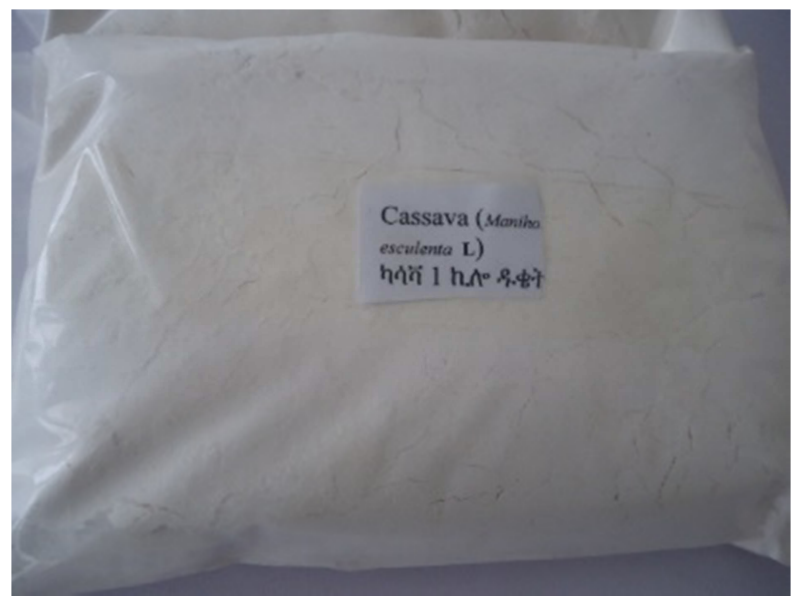

b

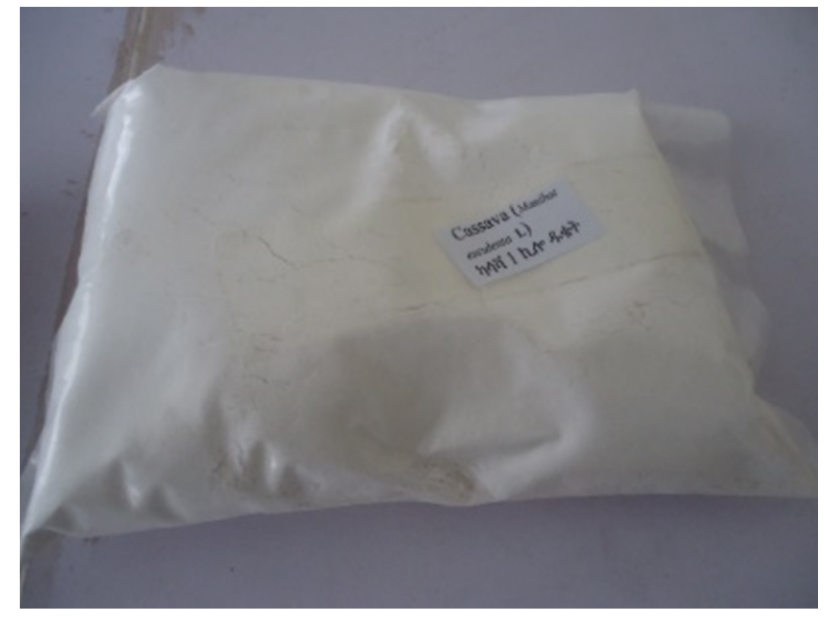

$\mathrm{c}$

Figure 3. Prepared cassava flours (a.oven b.sun c.tray).

\subsubsection{Water Activity Determination}

Water activity (aw) was determined in triplicate on finelyflour samples using an Aqualab (Decagon, Pullman, WA, USA) controlled witha sodium chloride standard solution $\left(\mathrm{a}_{\mathrm{w}}=0.75\right)$.

The water activity was determined in triplicate on finelyblended flour samples using Aqua Lab Lite water activity measuring unit manufactured by Decagon $\mathrm{a}_{\mathrm{w}}$ meter. Each sample of the prepared flours was half filled in a small plastic cup supplied with the instrument and inserted in to the instrument. The water activity of each sample was displayed.

\subsection{3. $P^{H}$ of the Flours}

The $\mathrm{pH}$ of the the dried sliced cassava tuber flour samples was determined by using digital $\mathrm{pH}$ meter. Standardization (calibration) of the $\mathrm{pH}$ meter was done usingbuffer solution of $\mathrm{pH} 7$ and 4. A $5 \mathrm{~g}$ prepared flour sample was dispersed in $25 \mathrm{ml}$ of distilledwater and allowed to stand for 30 minutes with constant stirring and dipping the electrode ofthe $\mathrm{pH}$ meter in to the dispersion with constant shaking until stable reading was obtained. Atequilibrium the value was recorded with the aid of $\mathrm{pH}$ meter. Triplicate determinations weremade in all cases.

\subsubsection{Titratable Acidity of Flours}

The total titratable acidity of the dried sliced cassava tuber flour samples was determined by [14], method. $5 \mathrm{~g}$ of the flour sample was macerated for 30 minutes in a beaker with $15 \mathrm{ml}$ ofdistilled water as 1 part of the flour to three parts of the water (w/v) ratio. A known volume of water is used for further dilution in order to hydrolyze all the acids in the sample. Beforetitration of the sample, the water that is used for dilution purpose will be titrated to be used asa blank. Three drops of $1 \%$ alcoholic phenolphthalein indicator was added to water extract ofthe sample (dispersion). The dispersion was then titrated with standard base $(0.1 \mathrm{~N} \mathrm{NaOH})$ tophenolphthalein end point. The result of determination will be reported as percentage lactic acid consuming definite volume of $0.1 \mathrm{~N} \mathrm{NaOH}$. The end point of the titration was reached when the white dispersion changed from a clear white solution to a faint violet colored turbidsolution. Triplicate determinations were made in all cases. Finally, it is given that the amountof lactic acid in the sample was determined from the relation $(1 \mathrm{ml} \quad 0.1 \quad \mathrm{~N} \quad \mathrm{NaOH}$ $=0.009008 \mathrm{mgC}_{3} \mathrm{H}_{6} \mathrm{O}_{3}$ ).

\subsection{Determination of Functional Properties}

\subsubsection{Bulk Density}

Bulk density was determined using the method of [2]. A sample of $7 \mathrm{~g}$ was measured into a $50 \mathrm{ml}$ graduated measuring cylinder. The cylinder was tapped continuously until a constant volume was obtained. The bulk density was calculated as weight of the prepared flours (g) divided by its volume in $\mathrm{ml}$.

\subsubsection{Water and Oil Absorption Capacity}

Water and oil absorption capacity of the dried sliced cassava tuber flour samples were determined according to [4]. One gram of the prepared flour was mixed with $10 \mathrm{ml}$ of distilled water (density $1 \mathrm{~g} / \mathrm{cm}^{3}$ ) or oil(specific gravity of $0.989 \mathrm{ml}$ ) in a centrifuge tube, mixed thoroughly with magnetic stirrer andallowed to stand at room temperature $\left(30 \pm 2^{\circ} \mathrm{C}\right)$ for one hour. It was then centrifuged at 200xgfor 30 minutes and the supernatant was transferred in a $10 \mathrm{ml}$ graduated cylinder. Water and oilabsorption capacity was calculated as $\mathrm{ml}$ of water or oil absorbed per gram of the flour.

Water and oil absorption capacity was calculated from the equation:

$$
\text { Water and oil absorption capacity }=10-\mathrm{V}
$$

Where V: volume of water or oil left unabsorbed after centrifugation.

\subsubsection{Foaming Capacity and Stability}

Foaming capacity and stability was determined by the method developed by [5]. One gram of the prepared flours was dispersed in 50 mldistilled water. The resulting solution was vigorously whipped for 30 minutes in a blender and poured into a $100 \mathrm{ml}$ graduated cylinder. The volume before 
and after whippingwas recorded and the foaming capacity was calculated as percentage volume increase.

The foaming capacity was calculated from the equation:

$$
\begin{aligned}
& \text { Volume increase(\%) } \\
& =\frac{\text { volume after whipping }- \text { volume before whipping }}{\text { volume before }} \times 100
\end{aligned}
$$

Foaming stability was determined as the volume of foam that will be remained after 2 hours with simultaneous recording of volume drop after every 10 minutes which is expressed as apercentage of the initial volume.

The foaming stability was calculated from the equation:

$$
\text { Volume of foam }(\%)=\frac{\text { Volume of foam after } 2 \text { hours }}{\text { initila foam volume }} \times 100
$$

\subsection{Cyanide Determination}

The cyanide content of the dried sliced cassava tuberswas determined by [2]. $20 \mathrm{~g}$ of prepared flour samples from dried slices were placed in extraction flask and followed by addition of $100 \mathrm{ml}$ of distilled water and allowed to stand for two hours, in order to set free all the bound hydrocyanic acid, meanwhile keeping the flask connected with an apparatus for distillation. After two hours of maceration, $100 \mathrm{ml}$ of distilled water was added to the slurry and steam distilled. The distillate was collected in $20 \mathrm{ml} 0.01 \mathrm{~N} \mathrm{AgNO}_{3}$ that has been acidified with 1 $\mathrm{ml} \mathrm{HNO}$. The distillation process was allowed to proceed for 40 minutes with vigorous boiling. After passing over of $150 \mathrm{ml}$ of the distillate, the distillate was filtered through Gooch with little water and the excess $\mathrm{AgNO} 3$ was titrated in combined filtrate and washings with $0.02 \mathrm{NKSCN}$, using ferric alum indicator. The end point of titration was indicated by appearance offaint reddish color up on addition of $0.02 \mathrm{~N}$ KSCN solution. The quantity of $\mathrm{HCN}$ present in the sample was calculated from the following relation

Volume (ml)of AgNO3 Consumed to complex CN $=20-$ $2 \mathrm{~V}$ of the titer $1 \mathrm{ml} 0.01 \mathrm{~N} \mathrm{AgNO} 3=0.27 \mathrm{mg} \mathrm{HCN}$

\subsection{Statistical Analyses}

The data obtained from the experiment were subjected to appropriate statistical tools of SPSS version 16.1. Comparisons between sample treatments was done using analysis of variance (ANOVA). Duncan's Multiple Range Test is used to identify significant differences by comparing means for processing method. Accordingly, ANOVA, mean comparison and significance was set at 5\% level.

\section{Result and Discussion}

\subsection{Physico-Chemical Properties of Cassava Flours}

The physico-chemical properties of cassava flours such as Moisture, $\mathrm{pH}$ Titratable acidity and water activity were determined and tabulated in table 1 .

(a) Moisture content

The low moisture observed for all prepared cassava flours is a good indicator of their potential to have longer shelf life. It is believed that materials such as flour and starch containing more than $12 \%$ moisture have less storage stability than those with lower moisture content. For this reason, a water content of $10 \%$ is generally specified for flours and other related products. It should be pointed out that when these products are allowed to equilibrate for periods of more than one week at $60 \%$ relative humidity and at room temperature $\left(25\right.$ to $\left.27^{\circ} \mathrm{C}\right)$, moisture content might increase.

(b) $\mathrm{p}^{\mathrm{H}}$ of flours

The $\mathrm{pH}$ of cassava flour is a good indicator of quality. Table 1 shows the physicochemical characteristics $(\mathrm{pH}$ and TTA) of the processed cassava flour. The $\mathrm{pH}$ value for prepared cassava flours ranged from 6.55 to 6.92. The present values are higher than the others previous worker report [10] which ranges from 3.8 to 7.2 and [6] who determined the $\mathrm{pH}$ value of cassava flour to vary from 4.6 to 7.2. This is due to the slices not pass through any processing methods except drying.

(c) Water activity

Water activity is an energy measurement which defines the amount of unbound water in a sample. It is one of the most important properties of food governing microbial growth. Most microorganisms cannot grow below water activity of 0.60 (i.e. no microbial growth occurs below $\mathrm{a}_{\mathrm{w}}$ of 0.50 ) with the majority growing at $\mathrm{a}_{\mathrm{w}} \leq 0.90$. Table 1 shows the water activity of cassava flour dried with different methods that in the range of 0.48 to 0.59 . All prepared flours predict lower water activity $(<0.5)$. These shows using the different drying methodologies the prepared flours were safe from any microbial growth during storage time.

Table 1. Effect of drying methodologies on physico-chemical properties of cassava flour.

\begin{tabular}{llllll}
\hline \multirow{2}{*}{ Drying Methodology } & \multicolumn{2}{l}{ Physico -chemical Properties } & & Titratable Acidity \\
\cline { 2 - 6 } & Drying time (h) & Moisture & Water activity & pH & $2.35 \pm 0.00^{\mathrm{a}}$ \\
\hline Tray dryer & 26 & $11.45 \pm 0.01^{\mathrm{a}}$ & $0.59 \pm 0.01^{\mathrm{a}}$ & $6.55 \pm 0.01^{\mathrm{a}}$ & $2.36 \pm 0.00^{\mathrm{a}}$ \\
Oven & 16 & $9.67 \pm 0.01^{\mathrm{b}}$ & $0.54 \pm 0.01^{\mathrm{b}}$ & $6.74 \pm 0.06^{\mathrm{b}}$ & $2.33 \pm 0.00^{\mathrm{b}}$ \\
Sun & 18 & $9.23 \pm 0.01^{\mathrm{c}}$ & $0.48 \pm 0.00^{\mathrm{c}}$ & $6.92 \pm 0.01^{\mathrm{c}}$ & 2 \\
\hline
\end{tabular}

Levels not connected by the same letter across the column are significantly different. Results are mean values of triplicate determination \pm standard deviation.

(d) Titratable Acidity

The titratable acidity is given in Table 1 for the prepared cassava flour samples. Titratable acidity in the range of 2.33-
2.36. The results of titratable acidity for the samples showed that they were less acidic in nature as compare to other workers like [1]. This is due to the present cassava flour not 
possess any fermentation processing techniques.

\subsection{Functional Properties of Flour}

The functional properties ofcassava flour samples are as shown inTable 2. These are bulk density, water and oil absorption capacity, foaming capacity andfoaming stability.

(a) Bulk density

Thebulk densities of cassavaflours are presented in Table 2 The resultrevealed that the bulk the density of tray, oven and sun driedcassava flour is $0.58,0.55$, and $0.49 \mathrm{in} \mathrm{g} / \mathrm{ml}$.

As compared to the bulk density of cassava flour reported by [13] which ranges from 0.64 to $0.76 \mathrm{~g} / \mathrm{ml}$ the Present value was somewhat lower. Bulk density gives an indication of the relative volume of packaging material required. Generally, higher bulk density is desirable for the greater ease of dispersibility and reduction of dough thickness which is an important factor in convalescent child feeding [16].

Table 2. Effect of drying methodologies on functional properties of cassava flour.

\begin{tabular}{llllll}
\hline \multirow{2}{*}{ Drying Methodology } & \multicolumn{3}{l}{ Functional Properties } \\
\cline { 2 - 6 } & Drying time (h) & BD (g/ml) & WAC (ml/g) & OAC (ml/g) & FC (\%) \\
\hline Tray dryer & 26 & $0.58 \pm 0.00^{\mathrm{a}}$ & $0.64 \pm 0.00^{\mathrm{a}}$ & $2.11 \pm 0.02^{\mathrm{a}}$ & $2.45 \pm 0.01^{\mathrm{a}}$ \\
Oven & 16 & $0.55 \pm 0.01^{\mathrm{b}}$ & $0.78 \pm 0.01^{\mathrm{b}}$ & $2.03 \pm 0.01^{\mathrm{a}}$ & $2.34 \pm 0.01^{\mathrm{a}}$ \\
Sun & 18 & $0.49 \pm 0.00^{\mathrm{c}}$ & $0.65 \pm 0.00^{\mathrm{c}}$ & $1.85 \pm 0.12^{\mathrm{b}}$ & $2.55 \pm 0.06^{\mathrm{b}}$ \\
\hline
\end{tabular}

Where: BD- bulk density, WAC -water absorption capacity, OAC- oil absorption capacity, FC- Foam capacity, FS-foam stability;Levels not connected by the same letter across the column are significantly different. Results are mean values of triplicate determination \pm standard deviation.

(b) Water and oil absorption capacity

Water absorption capacity gives an indication of the amount of water available for gelatinization and the ability of flour to absorb water, depends on the availability of hydrophilic groups which bind water molecules. Oil absorption is attributed to physical entrapment of oil and is important for flavour retention and mouth feel of foods. It is a critical assessment of flavour retention and increases the palatability of foods.

Oil absorption capacity is the ability of the flour protein to physically bind fat by capillary attraction and it is of great importance, since fat acts as flavor retainer and also increases the mouth feel of foods, especially bread and other baked foods. Variation in water and oil absorption capacity of flour samples may be due to different protein concentration, their degree of interaction with water and oil and possibly their conformational characteristics. The lower water absorption capacity of flour samples is due to less availability of polar amino acids and low-fat absorption may be due to the presence of large proportion of hydrophilic groups and polar amino acids on the surface of the protein molecules.

The WAC and OAC of the cassava flour samples are presented in Table 2. The WAC of cassava flour samples ranges 0.64 to $0.78 \mathrm{ml} / \mathrm{g}$. As compared to the value reported by [12] for processed cassava flour, the values obtained in this study are larger than the previously reported value which ranged from 1.37 and $1.26 \mathrm{ml} / \mathrm{g}$. Water absorption capacity describes flour - water association ability under limited water supply. The water absorption capacity of flour has been observed to be dependent on the starch and protein concentration in the material coupled with the size of the particles. Generally, the water absorption characteristics of the root flour is very important depending on the ultimate product to which the flour is intended to be converted which may include snack foods, extruded foods, and in bakery products.

Oil absorption capacity of tray oven and sun-dried cassava flours were $2.11,2.03$ and 1.85 respectively. The OAC value of cassava flour determined in this study is higher than the value reported by [13] which ranges from 1.07 to $1.13 \mathrm{ml} / \mathrm{g}$.
The lower oil absorption capacity of cassava flour in this study might be due to low hydrophobic proteins which show superior binding of lipids [15].

(c) Foam capacity and stability

The foaming capacities and stability of the processed cassava flour samples were presented in Table 2. The foaming capacity varies from $2.45 \%$ to $2.73 \%$. Foaming of the flour is the manifestation of protein content. Proteins will be denatured irreversibly by heat treatment and result in reduction of protein content of the flour. Therefore, the result of foaming capacity of cassava flour for dried sample obtained in this study is agreement with this fact.

From the result of foaming stability (Table 2), it shows that different drying methods influence foam stability of cassava flour samples. Foam stability ranges from 1.97-2.34\% of cassava flour samples. Tray dried cassava flours shows a higher foam stability.

\subsection{Cyanide Content}

The efficiency of different drying methods in reducing cyanide levels in cassavatubers was compared. Of the tuber samples analyzed, cyanide level was the highest in try dried cassava samples. The cyanide reduction rate is $34.9 \%$ using oven and $93.14 \%$ by sun drying as compare to tray drier. These show that drying methods had an impact on reduction of antinutritional factors. Hence sun drying it may due to the influence of the open environment to reduce the cyanide content.

Therefore, in order to remove totally the anti-nutritional factors in addition to using sun drying it is better combine other processing methods like fermentation, boiling etc...

Table 3. Effect of different drying methods on cyanide content.

\begin{tabular}{llll}
\hline & \multicolumn{3}{l}{ Drying Methodology } \\
\cline { 2 - 4 } & Tray dryer & Oven & Sun \\
\hline Drying time $(\mathrm{h})$ & 26 & 16 & 18 \\
Cyanide content $(\mathrm{mg} / 100 \mathrm{~g})$ & $2.03 \pm 0.12^{\mathrm{a}}$ & $1.32 \pm 0.0^{\mathrm{b}}$ & $0.14 \pm 0.02^{\mathrm{c}}$ \\
\hline
\end{tabular}

Levels not connected by the same letter across the raw are significantly different. Results are mean values oftriplicate determination \pm standard deviation. 


\section{Conclusion}

Drying is one of the methods that are used to preserve perishable food crops. Through appropriate drying methodology one can improve the quality of tuber flours. For this particular work oven drying shows a lower cyanide content and relatively tray dryer-based cassava flour had a good functional property. This will enable to be developing high quality cassava-based food products.

Sun and oven drying were observed to be faster than the tray drying. However, sun drying was more affordable and accessible than oven drying and it also gave the lowest moisture content in this study, suggesting a higher capacity to prevent microbial growth and decay in the prepared flour samples, thus, consults a greater increase in shelf life.

\section{References}

[1] Adebayo-Oyetoro Abiodun Omowonuo, Egbedinni Modesola Mary, Akinwande Femi Fidelis, Adeyeye Samuel Ayofemi Olalekan and Adeoya Adebayo Sunday. (2017). Quality Characteristics of Fermented Cassava Flour (Lafun) Produced Using Backslopping Method, EC Nutrition 7.2: 52-57.

[2] AOAC., 1995. Official Methods of Analysis. 16 ${ }^{\text {th }}$ Edn., Association of Official Analytical Chemists, Washington, DC., USA.

[3] AOAC., 2000. Official Methods of Analysis. 17 ${ }^{\text {th }}$ Edn., Association of Official Analytical Chemists, Washington, DC., USA.

[4] Beuchat, L. R., (1977). Functional and electrophoretic characteristics of succinylated peanut flour properties. J, Agric. FoodChemistry., 25: 258.

[5] Coffman, C. W. and V. V. Gracia, 1977. Functional properties and Amino acid content of a protein isolate from Mung beanflour. J. Food Tech., 12: 473.

[6] Daramola, B., \& Aina, J. O. (2007). Effects of Alum on Pasting and Some Physicochemical Properties of Cassava (Manihot esculentum) Starch. World Journal of Dairy \& FoodSciences, 2 (1): 18-22, 2007.
[7] Eke, J., Achinewhu, S. C., Sanni, L., Barimalaa, I. S., \& Dixon, M. B. 2007. Seasonalvariations in the chemical and functional properties of starches from local andimproved cassava varieties in high rainfall region of Nigeria. Journal of Food, Agriculture \& Environment, 5 (3\&4 ): 36-42.

[8] Elias, M., \& Mikey, D. 2001. Traditional management of Morphological and geneticdiversity by the Makushi Amerindians (Guyana, South America) Perspective for onform conservation of crop genetic resources. Euphytica,, 120 (1): $143-157$.

[9] Howeler, R. (2003). Cassava in Asia: Present Situation and its Future Potential inAgro-Industry.

[10] Kobawila, S. C., Louembe, D., Keleke, S., Hounhouigan, J., Gambe, C., 2005. Reductionof the cyanide content during fermentation ofcassava roots and leaves to produce bikedi andntoba mbodi, two food products from Congo. African J. Biotechnol. 4(7), 689-696.

[11] Mweta, D. E., Labuschange, M. T., Koen, E., Benesi, I. R. M. and Saka, J. D. K. (2008). Some properties of starch from cocoyam (colocasia esculenta) and cassava (Manihotesculenta Crantiz) grown in Malawi. African J. of Food Science. 2: 102111.

[12] Odoemelam S. (2003), Chemical composition and functional properties of conophor nut (Tetracarpidium conophorum) flour, International Journal of Food Science and Technology, $38,729-734$.

[13] Oladele, A. K., and Aina, J. O. (2007). Chemical composition and functional properties of flour from two varieties of figernut (Cyperus esculentus). African Journal of Biotechnology, 6(21):2473-2476.

[14] Pearson, D. A. 1976. The Chemical Analysis of Foods. 7th ed. Churchill Livingstone, Edingburgh.

[15] Udensi, E. A., Oselebe, H. O., Iweala, O. O. (2008). The Investigation of Chemical Composition and Functional Properties of Water Yam (Dioscorea alata): Effect of Varietal Differences. Pakistan J. of Nutrition 7: 342-344.

[16] Udensie. A. and Okoronkwo (2006). Effects of fermentation and germination on the physicochemical properties of Mucuna cochinchinensis protein isolate. African Journal of Biotechnology Vol. 5 (10), pp. 896-900. 